Dr. A. Brill's Method of Determining the Geographical Position in Aerial or Marine Navigation

Author(s): E. A. Reeves

Source: The Geographical Journal, Vol. 37, No. 4 (Apr., 1911), pp. 430-432

Published by: geographicalj

Stable URL: http://www.jstor.org/stable/1778412

Accessed: 17-04-2016 22:08 UTC

Your use of the JSTOR archive indicates your acceptance of the Terms \& Conditions of Use, available at

http://about.jstor.org/terms

JSTOR is a not-for-profit service that helps scholars, researchers, and students discover, use, and build upon a wide range of content in a trusted digital archive. We use information technology and tools to increase productivity and facilitate new forms of scholarship. For more information about JSTOR, please contact support@jstor.org.

The Royal Geographical Society (with the Institute of British Geographers), Wiley are collaborating with JSTOR to digitize, preserve and extend access to The Geographical Journal 
well presented. The use of dark grey for the lowest zone 0-300 metres is less attractive, though it combines well with the remainder of the scheme, but it would not allow any considerable amount of detail to show up on it effectively. Theoretioally the scheme has many advantages, and is said to need but four or five printings for the full scale, but the practical merits of this and other proposals which have been put forward (Pet. Mitt., Pl. 35, 1909) can only be adequately determined by experiments in which facility of reading form, legibility of detail, clearness of colours in both natural and artificial light, and many other points can be tried. But wherever colours are employed to reproduce the effect of relief the teachings of physiological optics should be kept in mind; and even where the object is only to differentiate one area from another by contrast of colour, the best effect will be obtained by their aid. Where graded tints of green, yellow, and red-brown have been used to produce a relief effect, the addition of a grey or violet for higher ground spoils the sequence and gives the effect of depressions where the highest ground lies. This may be seen in the Monmouth sheets of the "half-inch" layer map of the Ordnance Survey, and other sheets would show the same but that the half-tone shading is heavy enough to aid the relief effect. On large-scale maps, however, the surfaces are usually so large that the different colour tints hardly fall close enough to produce their full effect, and the result is in most cases rather a scheme of colour-contrast. In atlas plates, however, it is different, and in one recently published the relief effect of such a colour scheme was wholly nullified by the violet-grey used for the higher levels. Shading the hill slopes under conditions of inclined lighting is of great assistance in bringing up the relief effect, and in high ground where there is not much detail to be obscured it is very useful; but its value lies in showing the steeper slopes of major features, though smaller detail may be a good deal obscured by its use. Dr. Peucker uses this, the lighting being from the south. A very similar colour scheme is used on the new edition of the $1: 250,000$ map of Bavaria, with lighting from the north-west, and proves very effective, and in the international $1: 1,000,000 \mathrm{map}$, the seventeen colour-shades adopted by the committee are arranged much on the principles advocated by Dr. Peucker, except that while the browns grow darker with increasing height, the succeeding red group grow lighter in the same direction; also a pink colour is used instead of the vermilion of Dr. Peucker's aeronautic map.

H. G. L.

\title{
DR. A. BRILL'S METHOD OF DETERMINING THE GEOGRA- PHICAL POSITION IN AERIAL OR MARINE NAVIGATION.
}

\author{
By E. A. RERVes.
}

WITH the advance of aerial navigation attention has naturally been directed to the question of the most suitable method of determining the geographical position of an airship by astronomical observations of stars at night. On the continent, specially in Germany, quite a number of devices and ingenious arrangements have been brought out for the purpose during the past few years, the latest, and perhaps the most promising, of which is that described by Dr. Alfred Brill, of Frankford-a.-Main, in parts xi. and xii. of Annalen der Hydrographie for 1910 . 
What is, of course, aimed at in all of these methods is simplicity of observation and the minimum amount of computation, to ensure rapidity in arriving at the result. Under the circumstances, no great accuracy can be expected, or possibly obtained. In the first place, the altitude of the star has to be measured from the deck of the balloon with some special form of sextant fitted with a level which can only give approximate results; and then the methods of determining the position afterwards, to do away with computation as far as possible, are in great measure graphic, which necessarily renders refinement out of the question. Still, after all, if the position can be quickly found within a few miles, this is perhaps all that is required.

Most of the rapid methods proposed for determining the geographical position from astronomical observations, in their fundamental principle, depend upon some development of the 'Sumner Lines,' with which marine navigators are well acquainted, and have learned to esteem so highly, and the drawing of which can now be greatly simplified by the use of some of the numerous tables that have been computed to facilitate the operations.

The method described by Dr. Brill, which has been specially devised for aerial navigation, although it is equally suitable to the mariner, is a simple and ingenious development of finding the "position line" on the Saint Hilaire system. Still, whilst it is based upon this, it differs from it in many respects, and must to a great extent be considered original. It is interesting to learn that the method has secured a first prize at the International Aeronautical Exhibition recently held in Frankfurt.

A map of a special region to be traversed by the airship is drawn upon an equidistant zenithal projection, with true azimuths and distances from the central point, and printed on transparent material. This map is circular in form and mounted in a frame, so that it can be rotated and set to any required azimuth. The centre of the map, or the point of intersection between the central meridian and central parallel of latitude, is clearly marked, and for this point tables have been computed giving the altitude and azimuth of certain bright stars corresponding to their hour-angles from this point of the map. Covering the map, but independent of it so that the two can be turned round one on the other separately, is a sheet upon which is drawn a series of short sections of concentric circles of equal altitude; which appear nearly straight and represent "position lines"; and through the middle of these lines runs, at right angles to a tangent at their centre, a single straight line, answering to the "intercept" and bearing line, to be set to the bearing of the star. This covering sheet of sections of equal altitude circles is carried by a separate frame and attached at the ends to two rollers by which it can be rolled up or down so that any special altitude circle, or position line, can be made to pass through the central point of the map, and, owing to the material used being transparent, the map and the "position lines" can both be seen at the same time.

When it is required to determine the geographical position, the proceeding is as follows: An altitude of a suitable star is measured and the chronometer time (Greenwich or of some other meridian) noted, for which time the corresponding hour-angle of the star from the meridian passing through the centre of the map is quickly computed. With this hour-angle and the declination of the star, the table previously referred to is entered, and the corresponding altitude and azimuth of the star noted. Then, turning to the instrument, the altitude or "position line" sheet is moved up or down by turning the rollers until the 
line corresponding to the altitude taken from the table cuts through the centre point of the map, and the map is then turned round horizontally until the azimuth given in the table is indicated by the straight line which bisects the equal-altitude lines. The "intercept," or difference of altitude between the altitude shown by the line passing through the centre of the map and that observed, is then noted, and the equal-altitude line corresponding to this is the "position line" sumewhere upon which the observer is at the time the altitude was taken. The same operation is performed with another suitable star, or a latitude by Polaris is found, and the point of intersection of the two "position lines" fixes definitely, as usual, the observer's place on the map. In the example, of the working of this method given in Dr. Brill's account, a map of Germany and parts of adjacent countries is used, with the intersection of the $50^{\circ}$ parallel of latitude with the $10^{\circ}$ meridian east of Greenwich as the central point.

Dr. Brill's first article (in Heft xi.) is followed by a description, by Herr o. Voigt, of a special instrument for the plotting of position lines, constructed on this principle, which is intended for use at sea as well as in airships.*

Graphic methods of this description can only give approximate determinations, and the question is whether the accuracy that can be attained will be found to be sufficient for practical purposes, even provided the altitude can be measured with the required exactitude, which would be no easy matter in an airship. Another drawback to the system seems to be the necessity for having separate maps prepared, each with its own special central point, for which tables must be computed, and which, to be on sufficiently large scale, cannot include any very extensive area without becoming inconveniently large. Still, this latest method of determining the "position line" is decidedly ingenious, and, it is to be hoped, will be found of practical value.

\section{THE UGANDA-CONGO ARC.}

THE following communication has been received from Colonel C. F. Close, C.M.G., R.E., General Staff, for the Director of Military Operations:-

"I am directed to forward herewith a copy of the list of geodetic positions of the stations of the Uganda arc, rigorously computed from the work of the Anglo-Belgian Commission towards which the Royal Geographical Society contributed so liberally.

"It is intended to publish a full account of the operations and calculations connected with this work, and the second part of this publication will contain a discussion on local attraction, based on a comparison between the above positions and the astronomical latitudes now being computed by the Belgian astronomer, Monsieur Dehalu."

* In a third paper, printed in Heft ii. of the Annalen for 1911, Dr. Brill discusses the theory of the instrument. 